\title{
Evaluation of Green Hospital Dimensions in Teaching and Private Hospitals Covered by Tehran University of Medical Sciences
}

\author{
Farbod Ebadi Azar1, Fereshteh Farzianpour ${ }^{2 *}$, Abbas Rahimi Foroushani ${ }^{3}$, \\ Mahnaz Badpa4, Mohammad Azmal ${ }^{5}$ \\ ${ }^{1}$ Department of Health Management and Economics, School of Management, Iran University of Medical \\ Sciences, Tehran, Iran \\ ${ }^{2}$ Department of Health Management and Economics, School of Public Health, Tehran University of Medical \\ Sciences, Tehran, Iran \\ ${ }^{3}$ Department of Epidemiology and Biostatistics, School of Public Health, Tehran University of Medical Sciences, \\ Tehran, Iran \\ ${ }^{4}$ Health Services Management, Department of Health Management and Economics, School of Public Health, \\ Tehran University of Medical Sciences, Tehran, Iran \\ ${ }^{5}$ Health Services Management, Bushehr University of Medical Sciences, Bushehr, Iran \\ Email: ${ }^{\text {farzianp@sina.tums.ac.ir }}$
}

Received 15 January 2015; accepted 27 April 2015; published 30 April 2015

Copyright (C) 2015 by authors and Scientific Research Publishing Inc.

This work is licensed under the Creative Commons Attribution International License (CC BY). http://creativecommons.org/licenses/by/4.0/

(c) (7) Open Access

\begin{abstract}
"Green Hospital" has been emerged as an approach to address environmental challenges and meet the needs of society. The aim of this study was to evaluate the components of the Green Hospital in Teaching and Private Hospitals covered by Tehran University of Medical Sciences. The present study is a descriptive-analytical which examines the elements of the green hospital at 19 teaching and private hospitals covered by Tehran University of Medical Sciences in 2013. The checklist was developed by the Centre for Environmental Sciences Augsburg Germany which translated by Iranian Green's Management Association. The checklist consisted of eight Green Hospital dimensions which were used for data collection. Descriptive statistics measures including frequency tables mean and range and analytical statistics such as independent $t$-tests and analysis of variance (ANOVA) were used for data analysis. The studied hospitals have earned 59.5 percent of total points. In this regard, the dimensions of "environmental leadership and management" have rated the highest and water management is in the lowest rating. Although private hospitals had earned higher scores in all aspects of green hospitals apart from management and leadership and chemicals compared with teaching hospitals, but there wasn't any significant difference between these dimensions and types of hospitals statistically. Given that the hospitals studied do not meet green
\end{abstract}

${ }^{*}$ Corresponding author.

How to cite this paper: Azar, F.E., Farzianpour, F., Foroushani, A.R., Badpa, M. and Azmal, M. (2015) Evaluation of Green Hospital Dimensions in Teaching and Private Hospitals Covered by Tehran University of Medical Sciences. Journal of Service Science and Management, 8, 259-266. http://dx.doi.org/10.4236/jssm.2015.82029 
hospital standards properly, it seems necessary to prepare a comprehensive action plan to improve their weaknesses and meet these standards. Trying to perform a green hospital accreditation and receive certification of international authoritative institutions or developing a national standards is also recommended.

\section{Keywords}

\section{Green Hospital, Green Hospital Dimension, Teaching Hospital, Private Hospital}

\section{Introduction}

We are living in a moment in which the dual crises of public health and the environment are merging, the confluence of the two magnifying the destructive power of each. As they run together, the crosscurrents of disease and ecological deterioration build on one another, becoming increasingly turbulent and damaging forces that are tearing at the very fabric of our societies. Climate change, chemical contamination, and unsustainable resource use are all exacerbating ill-health the world over. The health sector itself is paradoxically contributing to these very environmental health problems, even as it attempts to address their impacts. Through the products and technologies it deploys, the resources it consumes, the waste it generates and the buildings it constructs and operates, the health sector is a significant source of pollution around the world, and therefore an unintentional contributor to trends that undermine public health [1].

Health care services consume large amounts of water and energy, use significant volume of hazardous and non-hazardous materials and are responsible for emissions [2]. In United State, hospitals are the second part of energy high consumptions and they consume energy twice that of conventional buildings [3]. Brazilian hospitals use more that $10 \%$ of the country's total commercial energy by consume vast amounts of energy [4]. The National Health System in UK has reported that it releases 25 million tones Carbone per year; on the other hand, 25\% of total gas production in the public sector [5]. In United State, hospital incinerations are one of the four main producers of Dioxin and Mercury [6].

Since hospitals provide health care to the communities, they are known through intrinsic link with social responsibility and sustainability aspects related to the environment and people [7]. Sustainability is the human requirement in the 21st century. For human societies, identifying sustainability requires systematic thinking, consisted decision making and accepting that human systems are located within the natural systems [8]. Therefore, hospitals should have a trend to protect the environment and try to implement the concept of sustainability. The concept of sustainability is essentially a response to the subjects related to the green hospital and includes various aspects of natural sciences, development of alternative energy and favorable energy storage systems [9]. Green Hospital is the hospital that constantly improves public health by reducing environmental impacts and eliminating the role of hospitals in cause burden of diseases. Green hospital recognizes the relationship between human health and environment and this shows that it is understandable through its governance, strategies and operations. Green Hospital connects local requirements with environmental measures and methods of primary prevention through active engaging in efforts to improve health of community and environment, health equity and green economy [1]. While there is no recognized and specific model of green hospital in the entire world, many of hospitals and health systems around the world simultaneously have taken steps to reduce their environmental impacts, help to public health and save money [1] [10]-[12].

There are determined goals due to successful implementation of green hospital program, including: leadership which is essential at all levels to foster green and healthy hospitals. This can be achieved through education, goal setting, accountability, and incorporating these priorities in all external relations and communications [1]. The health sector also consumes significant amount of chemicals. Through assessment the exposure of health institutes of with chemicals, health sector can protect patients and its staff and does actively safe management of chemicals [13]. Wastes also generated during caring activities have potential risk of infection and injury more than other type of waste [14]. However, it seems that some of the wastes produced in medical units have not been considered seriously, especially in developing countries [15]. Health sector uses significant amount of energy resulted from fossil fuels [16]. Hospitals can significantly reduce emission of greenhouse gases and costs of energy over the time through the use of alternative forms of clean and renewable energy [17]. Health care 
centers use large amounts of water. Climate changes with its associated effects such as drought, melting glaciers and depletion of aquifers have intensified water shortage [18]. It is recommended that all of these areas that need to water be evaluated and help to reduce water consumption [19]. Buildings in their current design are such boxes that convert sources to wastes. For this reason, they have immeasurable impacts on natural environment and life system. It should be considered in a sustainable framework. The only solution is Green building that means design and construction functions that reduce negative impacts on the environment. Hospitals and health systems purchase various types of products including chemicals, electronic and plastic materials to produce energy, drug and food [20]. Purchasing results in health sector have significant impact on environment [21]. Creation and implementation green purchasing policies such as purchase environmentally friendly products can play central role in achievement to green and healthy hospital purposes [17].

As mention above, green hospital has some goals which can contribute the hospital organization to move safety for their patients, staff and communities. Despite the establishment of Green Hospital in some countries of world, global efforts just address the climate change and protect the environment and the literature has been less paid to the green hospital. Although a lot of researchers have been separately worked on each of the green hospital dimensions including green building; unfortunately, the little research has been conducted about green hospital dimensions comprehensively [22]. In Iran also, some researchers have performed projects on this subjects such as hospital waste management, energy management in hospitals and assess accreditation standards of green hospital model have been done [23]-[28]. But, lack of a comprehensive study that includes all aspects of this approach and on the other hand, the necessity of protect environment by hospitals that are savior of health themselves, motivate us to evaluate dimensions of green hospital in all of teaching and private hospitals covered by Tehran University of Medical Sciences (TUMS).

\section{Method}

This is a descriptive-analytical study that evaluated green hospital dimensions in teaching and private hospitals under supervision of Tehran University of Medical Sciences in year 2014.

\subsection{Subjects}

The study population consisted of 31 hospitals under the supervision of Tehran University of Medical Sciences and the number of sample was calculated 19 based on sampling formula. After preparing the list of hospitals, they classified into 2 groups (private hospitals and teaching hospitals) and then, 9 teaching hospitals (from total 14 teaching hospitals) and 10 private hospitals (from total 17 private hospitals) were selected randomly.

\subsection{Instrument}

The data collection tools were check lists that evaluate 8 dimensions of green hospital and were created and developed by Center for Environmental Sciences, Augsburg, Germany [19]. These check lists were translated into Persian and were published by Iran Green Management Association [25]. These check lists have been reviewed and revised by several regional and international experts over periods and they have been implemented on a pilot basis. So, their validity and reliability have been proven. Kolmogorov-Smirnov (K-S) test was used to examine the normality of dimensions. Since the P-value in all 8 domains was greater than 0.05 , so the normality was approved.

These check lists consist of two main parts. The first section collect demographic information about hospitals includes type, age, workspace, number of staff, and number of active bed. The second section contains main items that assess 8 dimensions of green hospital. Check lists contain 244 items totally in a three-point range (Yes, No and Not Applicable) and each item was given a coefficient from 1 to 4 based on its importance. Required data were collected from responsible persons or their representatives in various units of 19 sample hospitals including clinical departments, administrative department, laboratory, laundry, environmental health, pharmacy, cafeteria and nutrition and energy after receiving introduction letter and acquisition of necessary permits. Table 1 shows dimensions, number of items (questions) and attainable score in each dimension.

Data were collected and were entered in SPSS 16 and then were analyzed in two parts: descriptive and analytical findings. Descriptive findings were shown by frequency tables, mean and variation. Analytical results were analyzed by statistical valid tests including T-test and one-way analysis of variance (ANOVA). 
Table 1. Specifications of check lists of Green Hospital standards.

\begin{tabular}{cccc}
\hline No. & Dimension & Items & Attainable score \\
\hline 1 & Leadership & 46 & 178 \\
2 & Chemicals & 25 & 74 \\
3 & Waste & 64 & 182 \\
4 & Energy & 41 & 94 \\
5 & Water & 29 & 64 \\
6 & Drug & 8 & 16 \\
7 & Building & 16 & 46 \\
8 & Purchasing & 15 & 38 \\
& Total & 244 & 692 \\
\hline
\end{tabular}

\section{Results}

From a total of 19 hospitals in sample, 9 hospitals (47.4\%) were teaching and 10 hospitals (52.6\%) were private. Workspace in 4 hospitals (21.1\%) was over than over than 30 thousand square meters, in 6 hospitals (31.6\%) was between 10 thousand to 30 thousand square meters and in 9 hospitals (47.4\%) it was under than 10 thousand square meters. 6 hospitals (31.6\%) had less than 100 active beds, seven hospitals (36.8\%) had more than 250 active beds and 6 hospitals (31.6\%) had between 100 and 250 active beds. 8 hospitals (42.1\%) were less than 45 years old, 6 hospitals (36.1\%) were between 45 to 70 years old and 5 hospitals (26.3\%) were over than 70 years old. Table 2 shows the frequency of obtained scores in each dimension.

As it is shown in Table 2, hospitals obtained only 59.5\% of total attainable score. Leadership obtained highest score and building obtained lowest.

According to the results, while average score in private hospitals was more than teaching hospitals in all dimensions except leadership and chemicals, there was no significant relationship between any of Green hospital dimensions and type of hospital statistically (P-value > 0.05) (Table 3).

Furthermore, based on our findings showed in Table 4, there was statistically significant relationship between chemicals and number of staff, energy and number of active beds, water and number of active beds, building and hospital age, purchasing and workspace (P-value < 0.05). Any statistically significant relationship between other Green hospital dimensions and hospital variables (age, workspace, number of active beds and number of staff) was not found.

\section{Discussion}

According to the results of this study, under study hospitals earned only $59.07 \%$ of total attainable score and they lost significant percentage in all of dimensions. In Shamir about effectiveness of environmental management study, Tehran's hospitals were not in good condition [29]. Leadership earned the highest score thought among all of Green hospital dimensions. Farzianpour's study y supports this result [24]. It seems that efforts and commitment of hospital managers to environmental aspects and establish the green and healthy hospital have had impact. Totally, it is advised to hospital managers to be aware of environmental lows and guidelines and commit to theme. Furthermore, it is recommended that administrators adopt global environmental systems such as ISO 14001 and Eco-Management and Audit Scheme (EMAS) to improve hospital activities in order that they can be able to monitor and evaluate their ongoing activities while they are lunching the system.

Dimensions of building, water and waste had lowest scores respectively while in Farzianpour's study dimensions of purchasing and chemicals had lowest scores [24]. About building, more than half of the hospitals in the study were older than 45 years. It is important to emphasize that the strategies of Green building are not applicable for new constructions. In many cases, existing buildings can be equipped to achieve many systemic improvements that are reaching in new buildings [19]. Based on scientific evidences, buildings should improve organizational performance and cause sustainability in the environment. So, the only practical solution to reduce 
Table 2. Frequency of obtained score in each dimension of Green Hospital.

\begin{tabular}{cccccc}
\hline Dimension & Number of hospitals & Total attainable score & Minimum & Maximum & Mean \pm SD \\
\hline Leadership & 19 & 178 & 90 & 162 & $112.89(63.42 \%) \pm 18.021$ \\
Chemicals & 19 & 74 & 29 & 71 & $46(62.1 \%) \pm 10.889$ \\
Waste & 19 & 182 & 74 & 132 & $103.16(56.7 \%) \pm 12.456$ \\
Energy & 19 & 94 & 46 & 76 & $56.95(60.6 \%) \pm 8.066$ \\
Water & 19 & 64 & 24 & 46 & $35.26(55.1 \%) \pm 6.190$ \\
Drug & 19 & 16 & 4 & 14 & $9.37(58.6 \%) \pm 2.587$ \\
Building & 19 & 46 & 12 & 38 & $24.37(53 \%) \pm 8.071$ \\
Purchasing & 19 & 38 & 16 & 30 & $23.68(62.3 \%) \pm 4.015$ \\
Total & 19 & 692 & 295 & 569 & $411.68(59.5 \%) \pm 8.781$ \\
\hline
\end{tabular}

Table 3. Relation between green hospital dimensions and type of hospital.

\begin{tabular}{|c|c|c|c|c|c|c|}
\hline \multirow{2}{*}{ Dimension } & \multirow{2}{*}{ Type } & \multirow{2}{*}{ Number } & \multirow{2}{*}{ Mean \pm SD } & \multicolumn{3}{|c|}{ Test } \\
\hline & & & & t & df & P-value \\
\hline \multirow{2}{*}{ Leadership } & Teaching & 9 & $108.67 \pm 13.528$ & \multirow{2}{*}{-0.969} & \multirow{2}{*}{17} & \multirow{2}{*}{0.346} \\
\hline & Private & 10 & $116.7 \pm 21.282$ & & & \\
\hline \multirow{2}{*}{ Chemicals } & Teaching & 9 & $50.11 \pm 9.955$ & \multirow{2}{*}{1.63} & \multirow{2}{*}{17} & \multirow{2}{*}{0.121} \\
\hline & Private & 10 & $42.3 \pm 10.833$ & & & \\
\hline \multirow{2}{*}{ Waste } & Teaching & 9 & $100.56 \pm 11.717$ & \multirow{2}{*}{-0.858} & \multirow{2}{*}{17} & \multirow{2}{*}{0.403} \\
\hline & Private & 10 & $105.5 \pm 13.243$ & & & \\
\hline \multirow{2}{*}{ Energy } & Teaching & 9 & $56.67 \pm 8.944$ & \multirow{2}{*}{-0.14} & \multirow{2}{*}{17} & \multirow{2}{*}{0.89} \\
\hline & Private & 10 & $57.2 \pm 7.671$ & & & \\
\hline \multirow{2}{*}{ Water } & Teaching & 9 & $34.22 \pm 7.032$ & \multirow{2}{*}{-0.685} & \multirow{2}{*}{17} & \multirow{2}{*}{0.503} \\
\hline & Private & 10 & $36.2 \pm 5.534$ & & & \\
\hline \multirow{2}{*}{ Drug } & Teaching & 9 & $9.11 \pm 2.028$ & \multirow{2}{*}{-0.402} & \multirow{2}{*}{17} & \multirow{2}{*}{0.693} \\
\hline & Private & 10 & $9.6 \pm 3.098$ & & & \\
\hline \multirow{2}{*}{ Building } & Teaching & 9 & $23 \pm 8.411$ & \multirow{2}{*}{-0.689} & \multirow{2}{*}{16.56} & \multirow{2}{*}{0.5} \\
\hline & Private & 10 & $25.6 \pm 7.989$ & & & \\
\hline \multirow{2}{*}{ Purchasing } & Teaching & 9 & $24.22 \pm 5.044$ & \multirow{2}{*}{0.543} & \multirow{2}{*}{17} & \multirow{2}{*}{0.594} \\
\hline & Private & 10 & $23.2 \pm 3.011$ & & & \\
\hline
\end{tabular}

Table 4. The relation between the Green Hospital dimensions and their demographic information.

\begin{tabular}{|c|c|c|c|c|c|c|c|c|}
\hline \multirow{2}{*}{ Dimension } & \multicolumn{2}{|c|}{ Hospital workspace } & \multicolumn{2}{|c|}{ Hospital age } & \multicolumn{2}{|c|}{ Staff number } & \multicolumn{2}{|c|}{ Active bed } \\
\hline & P-value & Test & P-value & Test & P-value & Test & P-value & Test \\
\hline Leadership & 0.25 & 0.975 & 0.24 & 0.750 & 0.89 & 0.497 & 0.42 & 0.660 \\
\hline Chemicals & 1.24 & 0.313 & 0.63 & 0.543 & 3.29 & 0.033 & 0.95 & 0.406 \\
\hline Waste & 0.18 & 0.835 & 0.06 & 0.936 & 0.65 & 0.531 & 0.64 & 0.681 \\
\hline Energy & 0.43 & 0.635 & 0.85 & 0.444 & 1.12 & 0.347 & 3.67 & 0.049 \\
\hline Water & 0.29 & 0.752 & 1.07 & 0.365 & 0.23 & 0.797 & 2.67 & 0.029 \\
\hline Drug & 0.73 & 0.497 & 1.36 & 0.297 & 1.72 & 0.209 & 1.36 & 0.297 \\
\hline Building & 1.31 & 0.300 & 5.39 & 0.016 & 0.15 & 0.858 & 2.67 & 0.769 \\
\hline Purchasing & 9.86 & 0.0200 & 0.44 & 0.648 & 2.84 & 0.081 & 0.65 & 0.555 \\
\hline
\end{tabular}


negative impacts of buildings on environment is Green building. In another words, buildings which consume lower energy and release lower Carbon in the atmosphere [20]. In this regards, changing in performance of existing buildings to use of daylight, natural ventilation, using of canopy and light reflectors, solar panels, solar water heaters and Green roof are recommended. Moreover, there are recognized standards to access hospital building and the best known of them are Green Star, BREEAM ${ }^{1}$ and LEED $^{2}$ [30]. These tools share a common concept: principles of Green building including used land, water and energy consumption, sourcing, environment and interior quality [31] [32]. Several studies have shown that hospitals which have became successful to get certificate, earn more benefits [20] [22] [33]. So, it is recommended to Iran's hospitals, especially private hospitals to try to get international reliable certificates. We advise to give energy label for buildings including hospitals (Such as domestic appliances), use integrated design process by contractors including Iran Housing Company and develop national standards for green hospital.

Findings of this study recognized water conservation management as priority for improvement. Studies of Farrokhshahi and Jabbarvand have estimated that water consumption in Iran's hospitals are 1.35 and 1.63 times the standard value respectively [20] [34]. Health facilities can protect water resources by accurate measurement of water consumption, installing efficient water equipment and technologies, development of drought-resistant perspective, and quickly repair the leaks [19]. Totally, hospitals obtained about $56 \%$ of total score in waste and it was a bit better in private hospitals. That was consistent with the findings of Farzianpour et al. [26]. Their study indicated that private hospitals were in better condition than teaching hospitals about the way of separation, collection, temporary storage and transportation of waste to temporary storage place in hospital and then to final disposal place. Hospital waste management including avoidance, reuse, recycling and disposal can be useful to reach one of the basic principles of green hospital, hospital waste management. Hospital administrators can manage waste through compost, recycle, better purchasing (downsizing package, use reusable products instead of disposables and buy recycled products) and minimize waste transport. By these actions, it will be possible to fulfill the hospital mission "no harm to patients, itself, society and environment" in addition to cost-saving [22]. It seems necessary to develop a comprehensive action plan in order to fulfill the fundamental standards and promote the weakness of Green hospital standards. There was no statistically significant difference among teaching and private hospitals. However, private hospitals attained higher score in all dimensions except of leadership and chemicals. It seems that private hospitals have more fund and their managers have more freedom to create a better picture of the quality of hospital services.

\section{Conclusion}

Hospitals should be revised in both structural and constructional aspects. Green Hospital will be achieved through strong commitment of health staff to take the leadership role in the prevention of health and environmental protection in the future. According to improvable points of green hospital standards, through developing operational plan, it will be possible to fulfill the hospital mission "no harm to patients, itself, society and environment" in addition to cost-saving. Moreover, trying to carry out evaluation and take certifications from international credible organizations such as LEED, GREEN STAR and BREEAM can help to improve the environmental management of the hospital. Considering the existing limitation, conducting a national comprehensive study yields the validation of obtained analytical results and allows us to generalize them.

\section{Acknowledgements}

The study is based on a M.Sc. thesis which supported by TUMS. We sincerely grateful all staff, managers and employees of selected hospitals covered by TUMS that helped us to conduct the study.

\section{References}

[1] Karliner, J. and Guenther, R. (2011) Global Green and Healthy Hospitals. Health Care without Harm (HCWH). https://noharm-europe.org/documents/global-green-and-healthy-hospitals-agenda-english

[2] Hancock, T. (2001) Doing Less Harm: Assessing and Reducing the Environmental and Health Impact of Canada's Health Care System. Canadian Coalition for Green Health Care. http://www.greenhealthcare.ca/resources/publications

\footnotetext{
${ }^{1}$ Building research establishment environmental assessment methodology.

${ }^{2}$ Leadership in energy and environmental design.
} 
[3] Kaiser, B., Eagan, P. and Shaner, H. (2001) Solutions to Health Care Waste: Life-Cycle Thinking and Green Purchasing. Environmental Health Perspectives, 109, 205-207. http://dx.doi.org/10.1289/ehp.01109205

[4] Salem Szklo, A., Borghetti Soares, J. and Tiomno Tolmasquim, M.C. (2004) Energy Consumption Indicators and CHP Technical Potential in the Brazilian Hospital Sector. Energy Conversion and Management, 45, 2075-2091. http://dx.doi.org/10.1016/j.enconman.2003.10.019

[5] Pencheon, D. (2009) Saving Carbon, Improving Health: NHS Carbon Reduction Strategy. National Health Service, Sustainable Development Unit. http://www.greenhealthcare.ca/resources/publications

[6] World Health Organization, Health Care without Harm (2009) Healthy Hospital, Healthy Planet and Healthy People: Addressing Climate Change in Health Care Settings.

http://www.who.int/globalchange/publications/healthcare_settings/en

[7] Kinney, L. (2010) Socially Responsible Hospitals Focus on Sustainability. Trustee, 63, 36.

[8] Dale, A. and Hill, S.B. (2001) At the Edge: Sustainable Development in the 21st Century. Vol. 6, UBC Press, Vancouver.

[9] Setyowati, E., Harani, A.R. and Falah, Y.N. (2013) Green Building Design Concepts of Healthcare Facilities on the Orthopedic Hospital in the Tropics. Procedia-Social and Behavioral Sciences, 101, 189-199. http://dx.doi.org/10.1016/j.sbspro.2013.07.192

[10] Natural Resources Canada. http://www.nrcan.gc.ca/publications/fossil-energy-future/1167

[11] Punpeng, T. (2011) GREEN and CLEAN Hospital. Oral Presentation at Asia Regional Conference for Mercury Free Health Care. Manila.

[12] National Health Service Sustainable Development Unit (2013) Route Map for Sustainable Health. http://www.sduhealth.org.uk/resources/default.aspx?q=Route+Map+for+Sustainable+Health

[13] Strategic Approach to International Chemicals Management (2011) Provisional Draft Strategy for Strengthening the Engagement of the Health Sector in Implementation of the Strategic Approach to International Chemicals Management. http://www.saicm.org/index.php?option=com content\&view=article\&id=221:iccm-2-health\&catid=89:iccm-2

[14] Cheng, Y.W., Sung, F.C., Yang, Y., Lo, Y.H., Chung, Y.T. and Li, K.C. (2009) Medical Waste Production at Hospitals and Associated Factors. Waste Management, 29, 440-444. http://dx.doi.org/10.1016/j.wasman.2008.01.014

[15] Shojaei, S. and Tehrani, H. (2004) Textbook of Preventive and Social Medicine (Persian). Samt Publication, 3.

[16] World Health Organization (2010) Health in the Green Economy: Co-Benefits to Health of Climate Change Mitigation. Health Facilities. Geneva.

[17] Health Care without Harm (HCWH) (2011) Global Green and Healthy Hospitals: A Comprehensive Environmental Health Agenda for Hospitals and Health Systems around the World. http://noharm.org/lib/downloads/building/GGHHA.pdf

[18] World Health Organization (WHO), Health Care without Harm (HCWH) (2009) Healthy Hospitals, Healthy Planet, Healthy People: Addressing Climate Change in Health Care Settings. 1-28. http://www.who.int/globalchange/publications/healthcare_settings/en

[19] (2005) Greener Hospitals. Improving Environmental Performance. Edited by: Environment Science Center, Augsburg, Germany with Support from: Bristol-Myers. http://www.bms.com/Documents/sustainability/downloads/greenh.pdf

[20] McDonald, R.C. (2005) The Economics of Green Building in Canada: Highlighting Seven Keys to Cost Effective Green Building. PhD Dissertation, Royal Roads University, Colwood.

[21] National Health Service (NHS). Saving Carbon, Improving Health, 45. http://www.sduhealth.org.uk/documents/publications/1237308334_qylG_saving_carbon,_improving_health_nhs_carbo n_reducti.pdf

[22] Azmal, M., Kalhor, R., Dehcheshmeh, N.F., Goharinezhad, S., Heidari, Z.A. and Farzianpour, F. (2014) Going toward Green Hospital by Sustainable Healthcare Waste Management: Segregation, Treatment and Safe Disposal. Health, 6, 2632-2640. http://dx.doi.org/10.4236/health.2014.619302

[23] Farrokhshahi, J. (2013) Survey of Accreditation Standards of Green Hospital Model in Selected Hospital Related to Social Security Organization in Kermanshah, Iran in 2012. National Conference of Quality Improvement with the Approach of Clinical Governance.

[24] Farzianpour, F., Hosseini, S., Mirsepasi, A., Honary, H., Hosseini, S.S. and Hosseini, S. (2013) Internal Evaluation of the Department of Environmental Health Science and Engineering. American Journal of Applied Sciences, 10, 58-63. http://dx.doi.org/10.3844/ajassp.2013.58.63

[25] Jabbarvand, M., Mokhtare, H., Sharifi, R., Shafiei, M. and Negahban, Z. (2011) A Comparative Study of Energy Consumption and Management at Farabi Aye Hospital, Tehran, Iran. Ebnesina Scientific Journal, 14, 41-48. 
[26] Farzianpour, F., Hosseini, S.H. and Hosseini, S. (2014) Global Change and Human Health. 2nd International Congress on Energy Efficiency and Energy Related Materials, Libery Hotels Lykia, Oludeniz, 16-19 October 2014, 365. www.enefm2014.org

[27] Emami, M.H. and Seraydaran, M. (2012) Guideline of Green Management (Specialized for Medical Universities, Hospitals and Healthcare Centers, Tehran, Iran). Iran Green.

[28] Farzianpour, F., Aghababa, S., Delgoshaei, B. and Haghgoo, M. (2011) Performance Evaluation a Teaching Hospital Affiliated to Tehran University of Medical Sciences Based on Baldrige Excellence Model. American Journal of Economics and Business Administration, 3, 272-276.

[29] Sahamir, S.R. and Zakaria, R. (2014) Green Assessment Criteria for Public Hospital Building Development in Malaysia. Procedia Environmental Sciences, 20, 106-115. http://dx.doi.org/10.1016/j.proenv.2014.03.015

[30] Green Guide for Health Care (GGHC) (2007) Best Practices for Creating High Performance Healing Environments. http://www.gghc.org/documents/Reports/GGHC_V2_Pilot_Report.pdf

[31] National Health Service (NHS). Saving Carbon, Improving Health, 54-55. http://www.sduhealth.org.uk/documents/publications/1237308334_qylG_saving_carbon,_improving_health_nhs_carbo n_reducti.pdf

[32] World Health Organization (WHO) (2010) Health in the Green Economy: Health Co-Benefits of Climate Change Mitigation. http://www.who.int/hia/hgehousing.pdf

[33] Guenther, R. and Vittori, G. (2008) Sustainable Healthcare Architecture. New York. http://eu.wiley.com/WileyCDA/WileyTitle/productCd-1118086821.html

[34] McDermott-Levy, R. (2011) The Nurse’s Role on Green Teams: An Environmental Health Opportunity. Pennsylvania Nurse, 66, 17-21. 